http://dx.doi.org/10.35381/racji.v5i8.594

\title{
La aplicación de los derechos humanos en el interés superior del niño
}

\section{The application of human rights in the top interest of the child}

\author{
Pablo Fernando Almeida-Toral \\ palmeidatoral@ucacue.edu.ec \\ Universidad Católica de Cuenca, Cuenca \\ Ecuador \\ https://orcid.org/0000-0002-2903-0583 \\ Juan Carlos Erazo-Álvarez \\ jcerazo@ucacue.edu.ec \\ Universidad Católica de Cuenca, Cuenca \\ Ecuador \\ https://orcid.org/0000-0001-6480-2270 \\ Diego Adrián Ormaza-Ávila \\ daormazaa@ucacue.edu.ec \\ Universidad Católica de Cuenca, Cuenca \\ Ecuador \\ https://orcid.org/0000-0002-3492-0943 \\ Cecilia Ivonne Narváez-Zurita \\ inarvaez@ucacue.edu.ec \\ Universidad Católica de Cuenca, Cuenca \\ Ecuador \\ https://orcid.org/0000-0002-7437-9880
}

Recibido: 15 de noviembre de 2019

Aprobado: 14 de diciembre de 2019

\section{RESUMEN}

La naturaleza tutelar del interés superior del niño es un elemento sobre el que se construyen derechos. El objetivo lograr una aplicación e interpretación uniforme de la directriz, a efectos de que las sentencia y resoluciones logren consolidar el principio de efectividad; se tomen decisiones jurisdiccionales y administrativas en consonancia con 
los derechos humanos lejos de la denominada lógica y razonamiento estándar, analizando las opiniones consultivas, y la Convención de Derechos Humanos. La metodología empleada en la investigación es de tipo cualitativa y se utilizó los métodos inductivos - deductivo; analítico sintético e histórico lógico. El resultado más relevante es rescatar el mecanismo de ponderación judicial en la aplicación de la directriz interés superior del niño en el análisis judicial para emitir fallos motivados.

Descriptores: Corte constitucional; Interés superior del niño; Tutela judicial efectiva; Opinión consultiva; Convención americana de derechos humanos.

\section{ABSTRACT}

The tutelary nature of the best interests of the child is an element on which rights are built. The objective is to achieve a uniform application and interpretation of the guideline, so that the sentences and resolutions consolidate the principle of effectiveness; jurisdictional and administrative decisions are made in line with human rights away from the so-called standard logic and reasoning, analyzing advisory opinions, and the Human Rights Convention. The methodology used in the research is qualitative and the inductive - deductive methods were used; synthetic analytical and logical historical. The most relevant result is to rescue the mechanism of judicial weighting in the application of the best interest guideline of the child in the judicial analysis to issue motivated decisions.

Descriptors: Constitutional court; Best interest of the child; Effective Judicial Guardianship, Advisory Opinion; American Convention of Human Rights.

\section{INTRODUCCIÓN}

El justiciable (usuario de la justicia) a la espera de que una autoridad judicial y administrativa cumpla con lo determinado en el Art. 76 numero 7 letra I) de la Constitución; esto es aplicar una de las garantías más apreciadas en el derecho constitucional el deber de motivar una decisión en una forma inteligible, razonable, comprensiva, aspecto inmerso dentro de la tutela judicial efectiva. No existe aquella si en una resolución y/o fallo no se precisan las leyes o principios constitucionales en los que se funda y no se transcriben cual es la pertinencia de su uso y evocación a los antecedentes de hecho factico; el artículo pretende reflexionar sobre la directriz 
principio del "interés superior del niño", su contenido se encuentra en la Convención Internacional de Derechos del Niño.

Los artículos 11 del CONA y 44 de la Constitución el Estado ecuatoriano, la Sociedad y la Familia en mentado orden se impulsa en lo judicial el correcto desarrollo integral de estos grupos de atención prioritaria y atenderán el principio indicado supra (Asamblea Nacional Constituyente, 2008, art. 44). El Derecho Constitucional y sus disposiciones en relación guían a la administración de justicia especializada como los niños niñas y adolescentes deben situarse constitucionalmente, la carta fundamental refiere de aquellos no solo como sujetos de protección y de atención prioritaria son objetivo de asignación de íntegros derechos; otorgándoles un nivel prevalente de garantismo constitucional, cuyo componente aunque no el único sea una respuesta judicial motivada con un contenido axiológico en la interpretación de la directriz pro infante.

Empero, el problema radica en que no existe claridad en la interpretación y aplicación del Interés Superior del Niño y Adolescente mismo sobre todo en los fallos y en los requerimientos del justiciable por intermedio de su defensor técnico especializado; pues existen vacíos en las peticiones que conlleva a considerar que el interés superior sea una idea de simple alegación para obtener un beneficio procesal, sin tener como base el horizonte de los derechos humanos en su aplicación lo que conlleva a lesionar la tutela judicial efectiva, y la atención prioritaria núcleos identificados en la presente investigación como básicos para lograr seguridad jurídica (Tamayo Vásquez \& Pino Loza, 2019).

Por lo tanto los fallos de la autoridad judicial sobre infancia deberían garantizar la seguridad jurídica atendiendo la directriz Interés Superior de la Niñez lo que conlleva a que las decisiones deben ser garantistas y motivadas resolviendo el problema jurídico de absoluta relevancia en conjunto con los principios rectores que rigen la justicia especializada, llámese humanidad, equidad sobre ritualidad del enjuiciamiento tomando como eje transversal no el criterio sino la argumentación judicial y a casos complejos incrementando la carga argumentativa considerando "los niños primero". 
Con los antecedentes expuestos lo que se pretende como objetivo es lograr una aplicación e interpretación uniforme de la directriz, evitando la falta de motivación de los Jueces de Familia en la aplicación del Interés Superior del Niño a efectos de que los fallos que sean emitidos, logren consolidar el principio de efectividad y se adecuen a una correcta tutela judicial efectiva limitando el margen de discrecionalidad de las autoridades pues aquello debilita la tutela de los derechos incluso del bloque de convencionalidad en materia de niñez y adolescencia; se tomen decisiones jurisdiccionales en consonancia con los derechos humanos lejos de la denominada lógica y razonamiento estándar, analizando las opiniones consultivas.

Este artículo no confronta la independencia judicial en los fallos ni menosprecia la utilización del razonamiento estándar en una decisión; defiende la presencia obligatoria en la actividad judicial de los argumentos maximizados en contenido axiológico que generen un trato diferenciado y que deben existir inexorablemente dentro del proceso intelectual de un operador de justicia dejando de lado su lógica y el razonamiento estándar, para ingresar a una argumentación que matice el verdadero significado de la denominada doctrina de protección integral que por mandato constitucional se debe aplicar consagrada en el Art. 175 de la Constitución.

\section{DESARROLLO}

\section{Enfoque de la Directriz (ISN)}

La Convención de los Derechos del Niño genera un nuevo horizonte de solucionar los conflictos, controversias de la niñez y adolescencia, tiene como base una doctrina denominada de Protección Integral; bajo un parámetro fundamental y eje central es considerado un niño-a y/o adolescente persona; con un sistema judicial y administrativo que sea respetuoso no solo de sus derechos sino también de su diversidad; para con ello generar el denominado garantismo de los grupos de atención prioritaria o especial; pues en esencia la doctrina protege derechos y crea un marco legal infraconstitucinal y supra constitucional para esta tutela, pues si bien son sujetos de derechos el enfoque 
no es solamente la protección de personas lo que ocasiona que se actué en forma diferenciada empleando estigmas y aspectos que puedan crear prácticas de discriminación.

En los procesos judiciales de protección de la niñez y adolescencia se encuentran fundamentalmente en todas y cada una de las decisiones judiciales; el enfoque de Interés Superior que emana no solo de la múltiple jurisprudencia sino en esencia de la doctrina de protección integral indicada supra; plasmada e ingresada en nuestra Constitución en su Art. 175, configurándose este principio (ISN) es el jefe central de decisiones administrativas, judiciales el argumento y alegación de los sujetos activos de la administración de justicia especializada; tal como ilustra su parte pertinente del Art. 44 de la norma normarum, se atenderá el principio de interés superior y sus derechos prevalecerán sobre los de las demás personas (Asamblea Nacional Constituyente, 2008).

La directriz de interés superior del niño está precisada en el artículo 3 de la Convención de los Derechos del Niño que en su parte pertinente determina: 1. En las decisiones que se tomen por parte de las instituciones públicas o privadas en el ámbito administrativo y judicial incluso los órganos legislativos, un aspecto relevante $y$ primordial a la que se atenderá en forma prioritaria y especial será el interés superior del niño".(Convencion America de Derechos Humanos, 1969)

Este principio tiene aceptación en el área del derecho no solo nacional sino también internacional pero su enfoque está direccionado a su deber ser el concebirlo no aislado sino en consonancia con los Derechos Humanos en su integralidad, es decir con el derecho de los derechos humanos, en relación la propia Corte Interamericana en su opinión consultiva OC17 la rescató como un eje fundamental al indicar: Este principio regulador de la normativa de los derechos del niño se funda en la dignidad misma del ser humano, en las características propias de los niños, y en la necesidad de propiciar el desarrollo de estos, con pleno aprovechamiento de sus potencialidades así como en 
la naturaleza y alcances de la Convención sobre los Derechos del Niño (Opinion Consultiva, 2002).

Además, en la Convencion de Ginebra (1924), se consagran por vez primera, en el ámbito internacional, los derechos de los niños y niñas, estableciéndose la obligación de darles lo mejor con la frase "primero los niños". En general la idea de interés superior de la niñez y adolescencia tiene un contenido de estudio normativo empero prima facie tiende a ser generalmente una regla aislada de consideración una guía, un principio genérico; para tomar una decisión judicial o administrativa tutelar o garante de estos grupos específicos de atención prioritaria; inter alias su uso está enmarcado en el denominado criterio deductivo o estándar, pero el desafío en este artículo surge al vincular ya sea como una regla, un principio o directriz a los consagrados derechos humanos donde es considerado el niño y adolescente una persona con de derechos humanos; para así situar su condición y casuística judicial en armonía doctrinaria con los tratados internacionales donde se verifiquen los principios pro infante en forma obligatoria con los atributos y características del contenido esencial de los propios derechos determinados en la Convención Interamericana de Derechos Humanos.

En relación varios autores lo precisan, entre quienes destaco este concepto de importancia "Es un principio jurídico interpretativo fundamental, toda vez que, si una disposición jurídica admite más de una interpretación, se elegirá la que satisfaga de manera más efectiva el interés superior de la niñez, y precisamente los derechos consagrados en la Convención sobre los Derechos del Niño y sus Protocolos Facultativos establecen el marco interpretativo" (Ojeda, 2004).

La idea de esta directriz muchas veces en la creación y elaboración de sentencias y resoluciones de tipo administrativa es de naturaleza subjetiva y vacía, que está sujeta y acorde a varios tipos de interpretaciones, incluso que si bien el principio está regulado en normas orgánicas en materia de niñez, no mantiene muchas de las veces ninguna relación a la dignidad misma del infante ni a sus principales bienes jurídicos protegidos, que surgen de sus derechos humanos; consecuentemente no debe analizarse 
simplemente una premisa, regla o directriz a considerar dentro del proceso argumentativo del operador de justicia especializado debe constituir y construirse un eje transversal que justifique la decisión del juez al caso concreto en rescate del garantismo, para lograr esta meta la directriz debe sostenerse inexorablemente en los principios universales de los derechos humanos conforme lo indicado supra.

Con ello el fin último en su aplicación es generar una argumentación con derechos fundamentales motivados, pues tanto los derechos humanos y los principios constitucionales armonizados entre aquellos tienen un solo horizonte motivacional, son pro infante al reconocer el ejercicio de sus derechos, de modo progresivo para satisfacer además los principios contenidos en la Convención pues "El interés del menor es un principio general del Derecho de Familia, debe ser este reinterpretado superando los viejos esquemas patriarcales que se regían por el deber ser de las cosas, reconociendo al niño como sujeto con capacidad natural principalmente en el ejercicio de sus derechos fundamentales". (Perea, 2008)

Tomar conciencia entonces de que la directriz no es simplemente el uso de una u otra denominación niño, infante menor de edad; no es alternativo, es importante para los profesionales que actúan con infancia la conciban desde todos los acercamientos o miradas: jurídico, psicológico, social, educativo, etc. (Valverde, 2016). Considerado aquello la autoridad judicial y administrativa tendrá las correctas denominaciones y utilización del tecnicismo idóneo; para una correcta aplicación al momento de argumentar al caso concreto en asuntos activados por parte legitimada sean sus padres, familiares o terceros.

\section{Vinculación a los Derechos Humanos}

En esta línea de análisis por otro lado, y en conexión íntima con lo anterior, la directriz analizada debe estar vinculada a los derechos humanos con una premisa inicial interés superior igual derechos humanos, si bien en el campo de la abogacía y su ejercicio profesional se concibe el derecho como un conjunto de normas que se aplican 
en uso a una razón, justificación o a una tesis, teoría del caso de la defensa técnica; es decir existe en la defensa y motivación, prevalencia de un razonamiento básico no se los reviste a los derechos reconocidos a favor de los niños un contenido y agregado axiológico, se genera una simple actividad intelectual y hermenéutica en forma aislada, sin tomarse en cuenta que el operador de justicia y autoridad administrativa debe adjudicar derechos bajo la fórmula ISN +contenido axiológico =adjudicación de derechos humanos para estos grupos de atención prioritaria.- Pero la interrogante ¿cómo se concretiza?.

Cuando un juez invoca el ISN como argumento o base en su decisión sin necesidad de explicar las reglas y/o principios que contienen el derecho reconocido o adjudicativo no existe un argumento judicial que supere la característica de estándar a contrario sensu cuando el juez en su resolución y decisión bajo la idea del primer elemento interés superior efectúa una posterior adjudicación con contenido axiológico a la solución del problema de relevancia jurídica, y explica sobre aquellos principios, reglas y normas se aleja de un razonamiento estándar, y vislumbra un horizonte garantista humanista, aplica los derechos humanos.

Aun pese a que las interpretaciones sean amplias en derechos humanos como son la libertad, integridad física y sicológica y principios de equidad, humanidad incluso sobre la ritualidad del enjuiciamiento; e igualdad de orden público es por tanto que lo único que garantiza que la decisión judicial se tomó en base al interés superior del niño y en el contexto de la Convención sobre Derechos del Niño, es lo que denominaré una correcta motivación adjudicativa de derechos humanos bajo la fórmula precisada, sobre la base de la ideas expuestas cuál es la conversión del razonamiento estándar a una argumentación adjudicataria vía motivación lógica y coherente; en la praxis la redacción general y la identificación de articulado textual en su contenido incluso respalda la obligación motivacional empero no se pondera y balancea con otras situaciones procesales y consideraciones; si partimos que la aplicación de la noción interés superior del niño adjudica derechos con contenido axiológico y opera en el juez 
la capacidad excluyente en este mecanismo; nace la idea de ponderación que en justicia especializada nos lleva al campo de la deducción argumentada, a la maximización de los derechos de la infancia mediante criterios sólidos de justificación judicial alejados de la lógica estándar.

Sin embargo para alcanzar en la mayor medida posible este objetivo debemos comprender de antemano con total transparencia que el ISN su definición y concepto en el modo de aplicación está ausente en la atmósfera codificada tanto en el bloque de Constitucionalidad, Convencionalidad y normas orgánicas, si bien es cierto no se cuenta con normas expresas predeterminadas que puedan aplicarse ipso facto al caso concreto, nuestra atención para su análisis se dirige y radica a las Observaciones del Comité de los Derechos del Niño en donde se contemplan orientaciones al referirse a la niñez con un presupuesto base de que su interés superior sea una consideración primordial, para el efecto para su interpretación deben entonces coadyuvar el estudio la identificación de los grupos de derechos protegidos el de supervivencia, los relacionados con el desarrollo del infante; los derechos de protección; y los de participación y cada uno de sus elementos aplicados siempre que se mantenga en forma sólida el carácter tutelar y garantista y el "pleno respeto del correcto desarrollo integral del niño-a y adolescente. (Comité de los Derechos del Niño de Naciones Unidas, art. 3, 2013).

Por lo tanto, la debida interpretación del interés superior del niño debe ser transparente, no aislada, simple o alejada de derechos humanos "Al ser el elemento sobre el que se construyen sus derechos, si no fuera porque los menores de edad gozan de un interés social fundamental carecerían de una regulación específica protectora de sus derechos" (Torrecuadrada García-Lozano, 2016). De lo expuesto si el objetivo son los derechos humanos es preciso considerar la tan argumentada protección convencional y los estándares de la Corte de Derechos Humanos para lograr aquella por intermedio de las medidas de protección como eje que asegure el cumplimiento de los cuatro derechos clasificados supra. 
El denominado derecho de los derechos humanos de los infantes si bien es cierto es sumamente amplio refiere al ámbito latinoamericano y tiene como eje central la Convención Americana sobre Derechos Humanos con ella se busca alcanzar la aplicación de derechos humanos en temas concretos de infancia tenencia, visitas, patria potestad incluso el mismo divorcio no bastan únicamente las reglas de lógica y tomar en consideración en forma aislada su interés superior mencionarla y decidir es necesaria considerar la normativa de la Convención Americana de Derechos Humanos argumentada y debidamente motivada; pues ninguna disposición de aquella puede limitar el goce y ejercicio de cualquier derecho o libertad que pueda estar reconocido de acuerdo con las leyes de cualquiera de los Estados Partes.

Consecuentemente la labor hermenéutica del juzgador debe estar por imperativo en consonancia con esta actividad intelectual al momento de emitir fallos se debe vislumbrar el derecho de los derechos humanos en niñez y adolescencia en forma integral mediante una expresión de dominio procesal pues una de las características inherentes a los derechos de infancia a diferencia de derechos fundamentales o humanos es su obligatoriedad son irrenunciables, pues ante la vigencia ante la vigencia del neoconstitucionalismo desde el año 2008, se genera un cambio, al implementarse un modelo de justicia y derechos pues el ámbito jurídico forma parte de la constitución y el estado ecuatoriano cumple con reconocer promocionar y garantizar los derechos de todos los ciudadanos con una distinción especial a los grupos prioritarios quienes tienen garantías materiales efectivas (Egas, 2010).

Pero no solo por mandato constitucional el estado tiene la obligación de promover el desarrollo de los grupos de atención prioritaria y asegurar el pleno ejercicio de sus derechos atendiendo el principio en análisis también está la familia y sociedad quienes deben atender sus derechos bajo el principio de prevalencia $\mathrm{n}$ sobre los de las demás personas, la infancia y adolescente tienen derecho a un desarrollo integral, entendido como proceso de crecimiento, maduración y despliegue de su intelecto y de 
sus capacidades, potencialidades y aspiraciones, en un entorno familiar, escolar, social y comunitario de afectividad y seguridad". (Asamblea Nacional Constituyente, 2008).

Con lo anotado se debe precisar que los Estados no solo deben asegurar los derechos de la legislación interna, tienen obligación de sujetarse a los instrumentos internacionales especialmente la Convención pues deben respetar sus derechos para así asegurar que aquella sea aplicada conforme la jurisdicción donde se encuentren domiciliados el sujeto de derechos; quienes son parte deben tomar cualquier medida apropiada que garantice y proteja formas incluso de discriminación por ideología, expresiones o pensamientos de los progenitores.- (Asamblea General de las Naciones Unidas, 1989).

La Corte IDH (1999) en el Caso de los Niños de la Calle, indica que los derechos "a la no discriminación, a la asistencia especial a los niños privados de su medio familiar, a la garantía de la supervivencia y el desarrollo del niño, al derecho a un nivel de vida adecuado y a la reinserción social de todo niño víctima de abandono o explotación" (Niños de la Calle" (Villagrán Morales y otros) Vs. Guatemala, 1999); ahora bien destaquemos el principio de prevalencia que alude nuestra Constitución debe ser entendido no solo como prevalencia propiamente dicha es sin duda la idónea y eficiente satisfacción del catálogo de derechos consagrados en la ley orgánica de infancia por intermedio de la correcta apreciación e intervención judicial, pues se deben considerar aspectos especiales que derivan de la dignidad humana del menor de edad; cuya génesis y origen está en su familia como núcleo fundamental, pues son quienes deben otorgan apriori la mayor protección posible; ya que se reconoce al entorno familiar como un elemento natural y fundamental de desarrollo de cada uno de sus integrantes.

Para asimilar el concepto de la directriz debemos comprender de mejor manera la idea de familia pues aquella no constituye únicamente la nuclear si bien son los padres biológicos a los que la Corte denomina progenitores los miembros de familia es comprendida según establezca además la costumbre de cada medio social , los tutores 
y demás parientes incluso de encargarse del cuidado y protección del infante pero en relación además a la forma de formación personal en cuanto a la dirección y orientación apropiada del niño para que ejerza los derechos reconocidos en la Convención ya indicada, como un instrumento de progresividad en el derecho internacional de los derechos humanos mediante compromiso de los Estados Partes es núcleo esencial de los derechos humanos (Luque, 2009) pues desde aquella concepción no se pueden alejar en su aplicación.

Con lo expresado supra se colige además que el administrador de justicia no solo debe abstenerse del razonamiento estándar, debe analizar el caso de vulneración de derechos mediante el mecanismo de ponderación en su pronunciamiento final, y durante la prosecución debe adoptar providencias proactivas con una correcta argumentación judicial considerando en cada una de sus actuaciones de trámite a la convención como un instrumento del ejercicio progresivo de sus derechos, esto exige que un Juez sea responsable de no someterse a un razonamiento de conclusión deductiva su obligación inexorable es resguardar a la familia como eje central; la protección de los niños-as involucrados mediante la adopción de medidas de protección que sean escudo de posibles y reales vulneraciones de sus derechos humanos y que promuevan la unidad familiar mediante óptimos procesos de reinserción.

Pero cuales son los ámbitos de protección que generan la aplicación del Interés Superior de la Niñez y Adolescencia, en relación a lo determinado por la Corte Interamericana quienes han determinado aspectos bases por intermedio de los siguientes dos pronunciamientos que merecen ser destacados:

El primer ámbito de protección es la vida digna conforme se destaca en la opinión consultiva (Corte Interamericana de Derechos Humanos, 2002).

El segundo ámbito es la obligación de proveer medidas para que la vida revista condiciones atinente a lo digno que trastoca incluso cuando la infancia y adolescencia se encuentra en situación de doble vulnerabilidad v.g a causa de discapacidad pues los estados reconocen que el niño mental o físicamente impedido debe disfrutar de una 
vida plena y decente en condiciones que aseguren su dignidad, le permitan llegar a bastarse a sí mismo y faciliten la participación activa del niño en la comunidad (Asamblea General de las Naciones Unidas, 1989).

\section{Motivación en los pronunciamientos judiciales}

Con las bases doctrinarias, su normativa constitucional, orgánica y positiva e identificados los parámetros bases de aplicación del interés superior explicaré como motivar en conflictos de familia donde se encuentren involucrados derechos de un niño, y se consolide finalmente la formula obtenida ya indicada, para aquello me referiré a explicar en breves rasgos el rol del juez; su modo actual de interpretar el interés superior del niño frente a su decisión, que valores y contenido axiológico brindó a la hora de fallar; que tipo de argumentación prevalece para garantizar una eficiente y correcta aplicación de la directriz que garantice una seguridad jurídica; el juzgador actual atiende únicamente el principio de legalidad mediante un razonamiento lógico que surge del silogismo hipotético para subsumir los hechos en determinadas normas y cuando aquellas encajan sin mayor inconveniente caso fácil se alega el ISN; pero que sucede en las zonas de penumbra donde se requiere otro tipo de argumentos y el conflicto tiene gradación por lo especial de las circunstancias fácticas; si bien la argumentación jurídica no está definida como doctrina específica en relación al Interés Superior del Niño; es claro también que la falencia radica el no analizar en forma previa los puntos cardinales antes indicados el alejarnos en la operación intelectual de la perspectiva de derechos fundamentales y aplicar cómodamente un razonamientos estándar; generando amplias redacciones sobre conceptos y copiado de artículos se creería que aquello daría soporte a una correcta motivación sin efectuar una verdadera ponderación y buscar la consonancia obligatoria con la Ley de la infancia, Código de la Niñez y Adolescencia; la Convención de Derechos Humanos y la Convención del Niño.

Como se ha precisado, sin duda alguna la directriz otorga derechos y son derechos humanos y aquellos al estar tanto en reglas como principios debe existir un mecanismo 
de ponderación; para ingresar al campo de la deducción con la selección de hechos acciones o sucesos que encajan en la norma y en el Derecho para demostrar que el hecho acaecido está en armonía con la disposición orgánica que en derechos de infancia seria lo deseable si lo que se pretende es adjudicar derechos humanos a niños niñas y adolescentes, por lo que corresponde a un Juez fallar no arbitrariamente sino con ponderación en relación al contenido esencial de la directriz; con verdaderos criterios rectores de la administración de justicia especializada; incluso en la aplicación del principio de equidad, y humanidad frente a la sola ritualidad del proceso.

El principio en estudio se constituye en un derecho esencial cuya función no solo se refiere al hecho de suplir dudas y vacíos sino debe constituir una verdadera ponderación de los derechos humanos, esta tendencia hace necesaria considerar a la ponderación como un método donde se establecen una relación de preferencia entre principios y normas, condicionada a las circunstancias del caso concreto y emitir un fallo correcto, adecuado y motivado pues cuanto mayor sea el grado de la no satisfacción o de afectación de un derecho o principio tanto mayor tiene que ser la importancia y de la satisfacción de otro, tarea prioritaria a la aplicación de la directriz.- (Asamblea Nacional del Ecuador , 2009).

El máximo organismo de control constitucional ecuatoriano en uno de sus dictámenes [Sentencia N. 064-15-Sep-C.C-caso N. (0331-12-EP determina: que el principio del interés superior del niño genera la base en materia de derechos, tiene aspectos primordiales que tiene reconocimiento no solo en la legislación interna sino que traspasa a ser estudiada como una norma de derecho internacional (Corte Constitucional del Ecuador, 2015).

En nuestro sistema jurídico, este principio lo garantiza la Carta del Estado pues por intermedio de aquella se asegura que estos grupos vulnerables tenga un integral desarrollo mediante procesos incluso de maduración, desarrollando capacidades intelectuales y se concreten aspiraciones en el entorno que se desarrollen en la 
comunidad con el apoyo incluso de políticas se los sectores estratégicos de apoyo como redes locales y nacionales.

La niñez frente a la administración de justicia no solo son sujetos de protección y de atención prioritaria sino asignatarios de íntegros derechos para lograr este objetivo considero necesario que un juez también se aleje de su instinto paternalista y/o maternal abandone su razonamiento estándar y guie su actuación al campo de la argumentación judicial sobre las rieles de los derechos humanos de la infancia y adolescente tomando como principio rector su interés superior ya explicado, pues la decisión judicial genera protección a sus derechos; aplicar la directriz sería proteger sus derechos; no solo en el ámbito judicial está la responsabilidad, aquella se dirige además a las instituciones no judiciales, las denominadas de funciones administrativas que deben tutelar mediante sus actos y decisiones también motivadas, pues por si sola se apega a una simple invocación, lejos de emitirse una sentencia, resolución, decisión o actuación razonable, coherente y respaldada en principios constitucionales y de derechos humanos.

Un fallo correctamente motivado y congruente según la Corte Constitucional sentencia No. 227-12-SEP-CC dictada en el caso No. 1212-11-EP; es aquel que la autoridad toma cuando expone el principio de razonabilidad y está presente con la sola lectura; el relato de razones y exposiciones debe ser además con lógica y completamente comprensible, tanto en el relato de los hechos cuando en la precisión de las normas aplicadas fundadas en principios constitucionales coherentes que sirvan en forma ordenada para decidir y concluir (Corte Constitucional, 2012).

Con lo resaltado en relación a la motivación es importante determinar finalmente además la prexistencia de dos principios transversales que son el margen de la aplicación de la directriz al caso concreto: el principio de exclusividad que crea órganos y autoridades que se dedican en forma específica en la administración de justicia en niñez y adolescencia con exclusión de otras materias y competencia; Jueces y Juezas especializados pues es obligación del Estado crear leyes procedimientos y órganos para 
brindar asistencia y trato diferenciado.

Este último debe tener como base una protección adicional, un aditivo los derechos humanos jamás una oposición o ausencia de los mismos; por lo que es vital procesalmente que los jueces aseguren un correcto acceso a la justicia y que la lógica de la aplicación de la ley sea el principio de igualdad con la construcción de razones argumentadas para que se determine cuando brindar un trato diferenciado, lejos de un trato paternalista y/o maternal, ni sentirse humanos por lo conmovedor que pueda ser la casuística familiar y ante la sensibilidad temporal tomar su decisión, pues aquello no es garantismo aquel se logra con la ejecución de los mecanismo asignatarios de principios humanos ponderados; dejando a flote prima facie la tutela judicial efectiva y atención prioritaria, que consagra la norma normarum y el bloque de convencionalidad.

\section{METODOLOGÍA}

La metodología empleada en la investigación es de tipo cualitativa, organiza conceptos y examina parámetros para extraer conclusiones sobre el tema abordado mediante silogismo deductivo de premisas mayores pero verdaderas buscando una conclusión que son obtenidas mediante inferencia hechas a partir del conocimiento ya existente utilizando los métodos inductivo - deductivo y analítico sintético; estos métodos permitieron aproximarse con la mayor certeza posible a una aplicación correcta de la directriz analizada y organización de los conceptos mediante la utilización del histórico lógico, se realizó el análisis de documentación como sentencias judiciales, se analizan casos particulares para obtener conocimientos generales, este método inductivo deductivo permitió el análisis de la doctrina, la leyes construyendo un aporte de aplicación teórica en la esfera del derecho constitucional (Panamá, Erazo, Narváez y Mena, 2019).

\section{APORTES GENERADOS}

Sobre lo expuesto durante el artículo se analiza lo siguiente:

La Convención de los Derechos del Niño genera una nueva forma de solucionar los 
litigios de la niñez y adolescencia, mediante la aplicación de la doctrina de Protección Integral; cuyo eje es un marco jurídico que proteja derechos de los niños considerados personas en arista se encuentra su dignidad y su correcto desarrollo integral en visión de los derechos humanos.

En los procesos judiciales de protección de la niñez existe un núcleo denominado principio de Interés Superior que constituye una directriz consagrado en la Constitución y en la Convención, esta aceptado en el derecho no solo interno sino internacional incluso motivo de opiniones consultivas emitidas por la Corte Interamericana de Derechos Humanos.

La noción de interés superior de la niñez y adolescente tiene un contenido únicamente normativo si no se considera el desafío de vincularlo con los derechos humanos lejos del criterio estándar para que constituya un principio jurídico interpretativo fundamental, no subjetivo ni vacío en rescate del garantismo.

La autoridad judicial tendrá la correcta visualización y una eficiente ponderación argumentativa siempre que utilice un razonamiento donde se de importancia o valor a los derechos humanos.

Un juez explica las reglas y principios que contienen el derecho judicializado y reconocido vislumbramos un horizonte garantista y tendremos certeza y no penumbra de lo que se decidió y fallo fue el resultado de una correcta motivación.

La autoridad judicial o administrativa será quien debe ponderar mediante un método deductivo argumentando, a la maximización de los derechos de la infancia mediante criterios sólidos de justificación judicial alejados de la lógica estándar.

En cada caso concreto, el niño será el centro de la decisión, se deberá descartar en la aplicación normativa condicionamientos y razonamientos subjetivos que atenten al contexto de protección.

Al mecanismo de aplicación de la directriz, por imperativo debe sumarse un agregado axiológico en la decisión., aquello permite el ingreso mediante ponderación al campo de la deducción con la selección de hechos acciones o sucesos fácticos que encajan en la 
norma para así demostrar que el hecho litigioso este en armonía con la disposición orgánica aplicable si lo que se pretende es adjudicar derechos humanos.

El operador de justicia debe decidir no arbitrariamente sino con una ponderación de verdaderos argumentos rectores en la administración de justicia especializada; incluso en la aplicación del principio de equidad, y humanidad frente a la ritualidad del proceso. Que la niñez y adolescencia en la administración de justicia no solo son sujetos de protección y de atención prioritaria sino asignatarios de íntegros derechos para alcanzar este objetivo la autoridad judicial y/o administrativa debe abandonar su instinto paternalista y/o maternal, su razonamiento estándar, para ingresar al campo de la argumentación judicial bajo la ponderación.

Se reconoce finalmente la prexistencia de dos principios transversales: el principio de exclusividad y especialidad con ellos surgen órganos y autoridades del estado que se dedican en forma específica en la administrar de justicia de niñez y adolescencia con exclusión de otras materias y competencia; y Jueces especializados para brindar asistencia y trato diferenciado, en el área su razonamiento amparado en el principio de igualdad en la aplicación de la ley dejando a flote la prima fase de la tutela judicial efectiva y atención prioritaria, que consagra la norma normarum en nuestro país. Dentro de este orden de ideas, se plantea en la siguiente figura el procedimiento propuesto: 


\section{OBJETIVO}

INTERES SUPERIOR DEL NIÑO
INCORRECTA APLICACIÓN EN LOS FALLOS JUDICIALES

INADECUADA MOTIVACIÓN JUDICIAL Y ADMINISTRATIVA

UTILIZACIÓN DE LA CONVENCIÓN

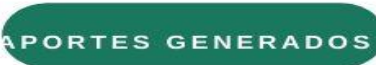
DE DERECHOS HUMANOS

AGREGADO AXIOLOGICO A LA APLICACIÓN DE LA ARAR CON ARGUMENTACIÓN JUDICIAL LA APLICACI
DIRECTRIZ

NO RAZONAMIENTO

ESTANDAR

EL NIÑO CENTRO DE ANÁLISIS AL CASO CONCRETO

Figura 1. Utilización de la Convención de Derechos Humanos sobre el Interés superior del niño.

\section{REFERENCIAS CONSULTADAS}

1. Asamblea General de las Naciones Unidas. (20 de noviembre de 1989). Convención sobre los Derechos del Niño. New York, Estados Unidos.

2. Asamblea Nacional Constituyente. (2008). Constitucion . Alfaro: Lexis.

3. Asamblea Nacional Constituyente. (20 de Octubre de 2008). Constitucion de la Republica del Ecuador. Alfaro, Manabi, Ecuador: Registro Oficial 449.

4. Asamblea Nacional del Ecuador . (22 de Octubre de 2009). Ley Orgánica de Garantíasd Jurisdiccionales y Control Constitucional. Quito , Pichincha, Ecuador: Registro Oficial Nro. 52.

5. Comite de los Derechos del Niño de Naciones Unidas. (2013). Observacion General . 14. Ginebra, Suiza: Naciones Unidas.

6. Convencion America de Derechos Humanos. (22 de Noviembre de 1969). Convencion America de Derechos Humanos. San Jose, Costa Rica: Conferencia Especializada Interamericana. 
7. Convencion de Ginebra . (1924). Recuperado de http://plataformadeinfancia.org/derechos-de-infancia/la-convencion-de-losderechos-de-la-infancia/?gclid=CjwKCAiA98TxBRBtEiwAVRLqu-enh3PTecWs7jYqCt8ZSIVavsv_6XAFIFD2hpJEWJ7Hbby0uZIUxoCD4EQAvD_BwE

8. Corte Interamericana de Derechos Humanos. (28 de Agosto de 2002). Opinión consultiva OC-17/2002. San Jose, Costa Rica: Secretaria de la Corte.

9. Corte Constitucional 21 de Junio de 2012. 1212-11EP. Recuperado de https://portal.corteconstitucional.gob.ec/FichaRelatoria.aspx?numdocumento=22 7-12-SEP-CC

10. Corte Constitucional 11 de Marzo de 2015. 0331-12EP. Recuperado de https://portal.corteconstitucional.gob.ec/FichaRelatoria.aspx?numdocumento=06 4-15-SEP-CC

11.Egas, J. Z. (2010). Derecho Constitucional, neoconstitucionalismo y argumentacion juridica. Guayaquil, Ecuador: Edilex.

12. La Convención Americana sobre Derechos Humanos. (1969). Conferencia Especializada Interamericana de Derechos Humanos. San Jose , Costa Rica.

13. Luque, M. d. (2009). Instrumento de progresividad en el derecho internacional de los derechos humanos. Cadiz, España.

14. Niños de la Calle" (Villagrán Morales y otros) Vs. Guatemala, (No. 11.383) ( Comisión Interamericana de Derechos Humanos 19 de Noviembre de 1999).

15. Ojeda Martinez, C. (2004). Estudio Critico sobre de los Derechos y Garantias de la Niñez y Adolescencia. Juridica.

16. Opinion Consultiva. (28 de Agosto de 2002). OC-17.

17. Panamá Chica, C. A., Erazo Álvarez, J. C., Narváez Zurita, C. I., \& Mena Clerque, S. E. (2019). El Marketing como estrategia de posicionamiento en empresas de servicios. Dominio de las Ciencias, 797.

18. Perea, J. M. (2008). Interés del Menor y Derecho de Familia Una Perspectiva Multidisciplinaria. Malaga: Lustel.

19. Tamayo Vásquez, F., \& Pino Loza, E. (2019). Derechos Humanos de los niños, niñas y adolescentes en los procesos Arbitrales. IUSTITIA SOCIALIS, 4(7), 97114. doi:http://dx.doi.org/10.35381/racji.v4i7.357 
20. Torrecuadrada García-Lozano, S. (2016). El interés superior del niño. Anuario Mexicano de Derecho Internacional. Mexico Distrito Federal, Mexico: Universidad Autónoma de Mexico.

21. Valverde, C. S. (2016). El interés superior del niño y de la niña. El debate Ideológico a traves de las Denominaciones Niño, niña o Menor. Barcelona: Visus Ipse.

(C2020 por los autores. Este artículo es de acceso abierto y distribuido según los términos y condiciones de la licencia Creative Commons Atribución-NoComercial-Compartirlgual 4.0 Internacional (CC BY-NC-SA 4.0) (https://creativecommons.org/licenses/by-nc-sa/4.0/). 